
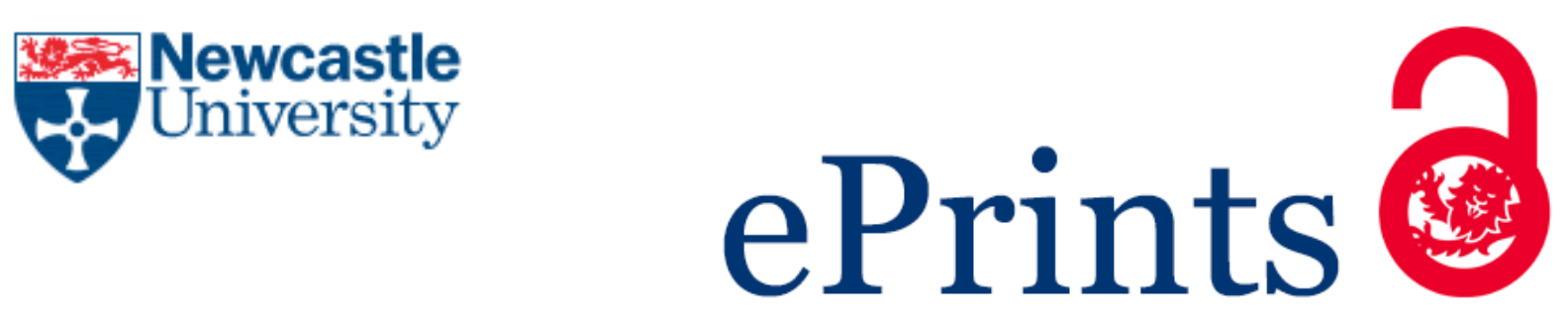

Widmer JD, Martin R, Mecrow BC.

Pre-Compressed and Stranded Aluminium Motor Windings for Traction

Motors.

IEEE Transactions on Industry Applications 2016

DOI: 10.1109/TIA.2016.2528226

\title{
Copyright:
}

(C) 2016 IEEE. Personal use of this material is permitted. Permission from IEEE must be obtained for all other uses, in any current or future media, including reprinting/republishing this material for advertising or promotional purposes, creating new collective works, for resale or redistribution to servers or lists, or reuse of any copyrighted component of this work in other works.

DOI link to article:

http://dx.doi.org/10.1109/TIA.2016.2528226

Date deposited:

$20 / 11 / 2015$ 


\section{Pre-Compressed and Stranded Aluminum Motor Windings for Traction Motors}

\author{
James D. Widmer \\ Newcastle University \\ Newcastle-upon-Tyne \\ NE1 7RU, UK \\ james.widmer@ncl.ac.uk
}

\author{
Richard Martin \\ Newcastle University \\ Newcastle-upon-Tyne \\ NE1 7RU, UK \\ richard.martin2@ncl.ac.uk
}

\author{
Barrie C. Mecrow \\ Newcastle University \\ Newcastle-upon-Tyne \\ NE1 7RU, UK \\ barrie.mecrow@ncl.ac.uk
}

\begin{abstract}
There are benefits if copper windings are replaced with aluminum in applications which are cost and mass sensitive, such as automotive traction; these include the low cost of aluminum, low mass of aluminum and the ease of motor recycling at end of life. However the relatively low electrical conductivity of aluminum compared to copper needs to be overcome. Precompressed motor coils have been shown to produce very high fill factors (>75\%), reducing DC winding losses, therefore enabling the use of aluminum conductors. However the single stranded conductors used can be prone to high AC losses due to skin and proximity effects. Therefore a method of manufacture of precompressed coils made from stranded / Litz wire is needed, allowing AC losses to be reduced to low levels. This paper describes the development and test of stranded, pre-compressed aluminum coils which have been developed for use in an automotive traction application.
\end{abstract}

Index Terms-- Windings, Aluminum Conductors, Electric Machines, Traction Motors

\section{INTRODUCTION}

$\mathrm{C}$ OPPER is commonly used in the windings of high performance electrical machines. This is due to its high electrical conductivity, enabling high current density motor designs which minimize DC winding losses. However there are a number of potential benefits in the use of aluminum windings, $[1,2]$ :

- Aluminum has a mass density only $30 \%$ of that of copper, this can be beneficial in applications where low mass is important;

- Aluminum is significantly cheaper than copper, having a cost approximately $30 \%$ of copper per unit mass, or $10 \%$ per unit volume [3];

- Aluminum can be recycled with steel, whereas copper is a considerable contaminant in the steel recycling process. For many high power density motor designs it is difficult to separate the windings from the steel core without significant dismantling processes, making this an important consideration [4].

Aluminum has been widely used as an electrical conductor for many years in applications such as power distribution and low cost electrical machines, particularly in induction machine rotors [5, 6]. However its use has not been reported in high power density electrical machines, probably due to its lower electrical conductivity than copper. The authors have previously presented a $6 \mathrm{~kW}$ electrical machine, designed for use in an aerospace application, which used pre-compressed aluminum coils, maintaining motor losses at the required level whilst reducing motor mass by more than 10\% [7]. The compression process, first presented in [8], allows a very high fill factor to be achieved (>75\%) where single stranded conductors are used. This allows the lower conductivity of aluminum, when compared to copper, to be offset whilst still retaining the benefits of low mass.

This paper describes how pre-compressed aluminum coils now also featuring, for the first time, multi-stranded and transposed conductors, important where AC losses must be minimised, have been developed for use in an $80 \mathrm{~kW}$ automotive application (Fig. 1). This paper also offers new insights, beyond those previously presented in [7], in two other areas; firstly in that the winding coils are physically much larger (factor of 30 increase in mass) than those previously reported, creating new manufacturing challenges, and secondly that they are required to operate in a torque and power dense electrical machine, creating new challenges in terms of thermal performance. Whilst the focus of this paper is on the use of aluminum conductors, the compression process may equally be applied to copper windings.

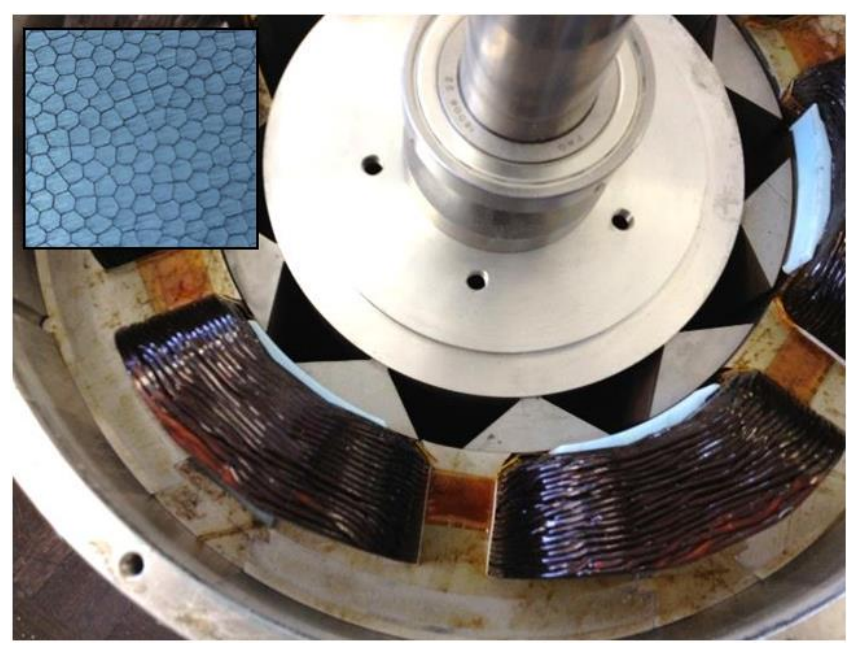

Fig. 1. 80kW Segmental Rotor SRM with Pre-Compressed Aluminum Motor Windings. Insert shows magnified coil section.

\section{Segmental Rotor SRM Traction Motor}

In recent years there has been uncertainty about the cost and availability of the rare earth magnets commonly used in traction motors for electric vehicles [9]. One alternative considered by the authors has been the Segmental Rotor 
Switched Reluctance Machine (SRM). This machine has been shown to offer torque per unit loss advantages over conventional SRMs $[10,11]$ and as a result has been optimised for use in a traction application [12]. In [12] the objective has been to closely match the performance of the $80 \mathrm{~kW}$ Interior Permanent Magnet Motor used in the Nissan Leaf Electric Vehicle. Similar performance with similar mass has been demonstrated with this Segmental Rotor SRM (Fig 2), though the resulting motor has been volumetrically larger than the baseline machine. There are also challenges inherent in the development of Segmental Rotor SRMs, for use in this application, which are not addressed in this paper; they include the potential for high levels of acoustic noise and torque ripple. Further work is ongoing in these areas and the authors will report back in future papers.

However, given the larger size of the Segmental Rotor SRM compared to the Nissan Leaf's IPM, the maintenance of similar motor mass has been possible in large part due to the use of pre-compressed aluminum motor coils. Design information is provided in Table 1.

TABLE 1. 80KW SRM PARAMETERS COMPARED TO NISSAN LEAF INTERIOR PERMANENT MAGNET MOTOR

\begin{tabular}{|l|l|l|}
\hline & $\begin{array}{l}\text { 80kW Prototype } \\
\text { Segmental Rotor } \\
\text { SRM }\end{array}$ & $\begin{array}{l}\text { Nissan Leaf } \\
\text { Interior Permanent } \\
\text { Magnet [13] }\end{array}$ \\
\hline Max Speed & $10,390 \mathrm{rpm}$ & $10,390 \mathrm{rpm}$ \\
\hline DC Voltage & $600 \mathrm{~V}$ & $400 \mathrm{~V}$ \\
\hline Max Torque & $280 \mathrm{Nm}(200 \mathrm{Arms})$ & $280 \mathrm{Nm}(340 \mathrm{Arms})$ \\
\hline Peak Power & $80 \mathrm{~kW}$ & $80 \mathrm{~kW}$ \\
\hline Phases & 3 & 3 \\
\hline Stator Slots & 12 & 48 \\
\hline Rotor Configuration & Segmental rotor, & $\begin{array}{l}\text { Interior permanent } \\
\text { magnet, } 8 \text { poles }\end{array}$ \\
\hline Active Diameter & 10 segments & $200.4 \mathrm{~mm}$ \\
\hline Active Length & $246.1 \mathrm{~mm}$ & $231.5 \mathrm{~mm}$ \\
\hline Active Volume & $224.2 \mathrm{~mm}$ & 7.31 \\
\hline Active Mass & 10.61 & $32.0 \mathrm{~kg}$ \\
\hline Power Density & $32.7 \mathrm{~kg}$ & $2.5 \mathrm{~kW} / \mathrm{kg}$ \\
\hline Torque Density & $2.5 \mathrm{~kW} / \mathrm{kg}$ & $8.8 \mathrm{Nm} / \mathrm{kg}$ \\
\hline NdFeB Magnet Mass & $8.6 \mathrm{Nm} / \mathrm{kg}$ & $\sim 2.00 \mathrm{~kg}$ \\
\hline
\end{tabular}

\section{MOTOR WINDING REQUIREMENTS}

In many respects the development of the compressed aluminum coils is independent of the motor technology considered. Such coils could equally be used in other electrical machine topologies with single tooth windings; however the selected motor design does illustrate the imperative for the development of pre-compressed and stranded coils if aluminum is to be used:

- Segmental Rotor SRMs, not benefitting from the field provided by permanent magnets, are reliant on high electrical loadings to develop competitive torque densities. This drives the need for winding compression as a method for reducing DC loss whilst also enabling good thermal transfer from the motor coils [7];

- The machine is designed to operate at circa $10,500 \mathrm{rpm}$ and has a 10 pole rotor; as the motor is based on unipolar switched reluctance technology this therefore results in a high electrical frequency $(1.75 \mathrm{kHz})$. With an automotive standard DC link voltage $(\sim 400 \mathrm{~V})$, this implies a relatively low number of winding turns per phase, resulting in large diameter conductors. As a result, the high electrical frequency results in the requirement to mitigate high AC winding losses in the motor windings; this drives the requirement to use stranded conductors;

- The electrical machine should be able to operate at high continuous power ratings. Therefore it must be possible to readily remove heat from the motor's windings, leading to the need for a high cross-slot thermal conductivity;

- This is intended to be a low cost, mass competitive motor design. Therefore the cost and weight of the motor windings must be minimized.

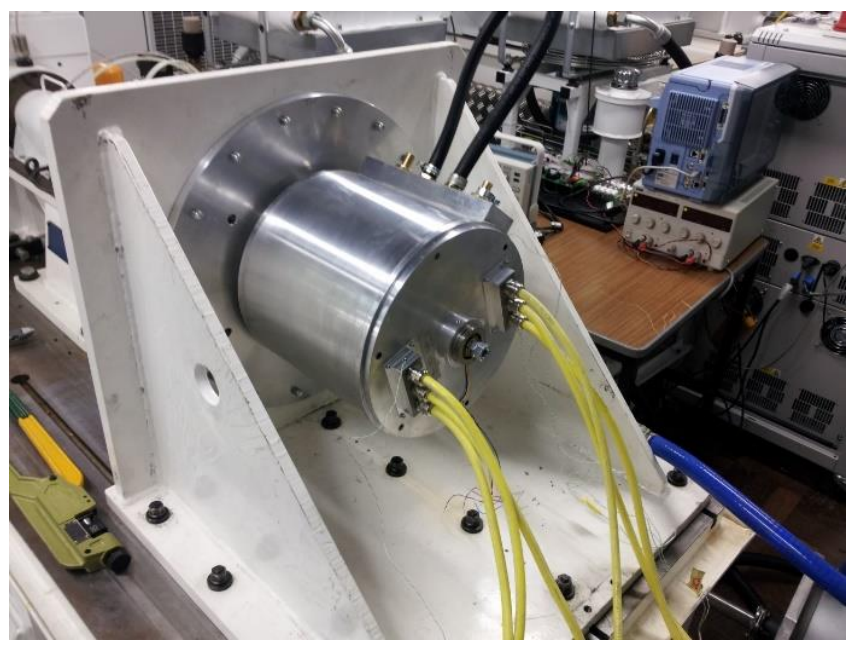

Fig. 2: 80kW Segmental Rotor SRM fitted with Pre-Compressed Aluminum Windings. (Left), internal view of motor windings, (right) motor on test.

As can be seen, the requirements for the Segmental Rotor SRM's windings are representative of those of any traction motor. Therefore the general implications of the use of aluminum windings are summarized in the following sections:

\section{A. $\quad$ Minimised DC Loss}

The electrical conductivity of aluminum windings is lower than for copper, thus the resistance per unit winding length will be higher, as is shown in (1):

$$
\partial_{R}=\frac{R_{A l}}{R_{C u}}=\frac{\sigma_{C u} S_{F F}^{C u}}{\sigma_{A l} S_{F F}^{A l}} \cong 1.64 \frac{S_{F F}^{C u}}{S_{F F}^{A l}}
$$

where $R$ is the resistance, $\sigma$ is the winding material's electrical conductivity, $S_{F F}$ is the slot fill factor, and at $20^{\circ} \mathrm{C}$ the electrical conductivities are $\sigma_{C u}=58.0 \times 10^{6} \mathrm{~S} / \mathrm{m}$ and $\sigma_{A l}=$ $35.4 \times 10^{6} \mathrm{~S} / \mathrm{m}$. Both materials have similar thermal coefficients of electrical conductivity, hence this ratio remains valid across a wide range of temperatures.

Hence, in order to achieve an aluminum winding resistance comparable to that of copper, for a given slot size, a higher fill 
factor must be achieved.

\section{B. Minimised AC Winding Losses}

$\mathrm{AC}$ winding losses can be a significant concern in high power density electrical machines. One element is the skin depth $(\delta)$, which may lead to an increase in winding resistance where high electrical frequencies are required. Skin depth is inversely proportional to the square root of the material conductivity, therefore it follows that the ratio of skin depth between aluminum and copper conductors is as follows:

$$
\partial_{\delta}=\frac{\delta_{A l}}{\delta_{C u}}=\sqrt{\frac{\sigma_{C u}}{\sigma_{A l}}} \cong 1.28
$$

However in most electrical machine applications, whether the conductor is aluminum or copper, it is possible to specify a conductor diameter of less than two skin depths, minimizing this effect. Proximity effects, namely eddy currents induced by cross slot leakage flux, are potentially more significant and can be estimated using the following expression [14]:

$$
P_{a c}=\frac{\pi}{64} \cdot \sigma \cdot l \cdot d^{4} \cdot \frac{d B^{2}}{d t}
$$

where $P_{a c}$ is the proximity loss in $\mathrm{W}, \sigma$ is the electrical conductivity of the winding material, $d$ is the diameter of the conductor and $B$ the instantaneous magnetic flux density. Proximity losses are proportional to material conductivity, and assuming the same strand diameter the ratio between AC losses in aluminum and copper conductors will be:

$$
\partial_{P(a c)}=\frac{P_{a c}^{A l}}{P_{a c}^{C u}}=\frac{\sigma_{A l} \cdot d_{A l}^{4}}{\sigma_{C u} \cdot d_{C u}^{4}}=\cong 0.61 \frac{d_{A l}^{4}}{d_{C u}^{4}}
$$

However the reality is more complex; if the analysis takes into account the increase in aluminum strand diameter required to equalise DC losses in the two conductors then the situation reverses with:

$$
\partial_{P(a c)}=\frac{\sigma_{A l} \cdot\left(1.28 \cdot d_{C u}\right)^{4}}{\sigma_{C u} \cdot d_{C u}^{4}} \cong 1.64
$$

where the losses will in fact be higher in the aluminum conductor.

However in both the case of copper and aluminum windings this can be mitigated through the use of stranded conductors in order to reduce AC proximity losses to a reasonable level. These conductors will also need to be transposed in the slot if circulating currents between conductors are to be avoided.

\section{High Thermal Conductivity}

In order to remove heat from motor windings, a high cross slot thermal conductivity is important. This will allow heat to migrate from the coil to the motor laminations and hence to the motor water jacket. Cross slot thermal conductivity can be approximated as follows [6]:

$$
\lambda_{e q}=\lambda_{\text {air }} \frac{\left(1+S_{F F}\right) \lambda_{a l}+\left(1-S_{F F}\right) \lambda_{\text {air }}}{\left(1-S_{F F}\right) \lambda_{a l}+\left(1+S_{F F}\right) \lambda_{\text {air }}}
$$

where the $\lambda_{\text {air }}$ is the thermal conductivity of the air and $\lambda_{a l}$ is the thermal conductivity of the aluminum. The thermal conductivity of the winding insulation is initially neglected on the grounds that it is much higher than that of air. If the thermal conductivities of aluminum and copper are compared, the following ratio results:

$$
\partial_{k}=\frac{\lambda_{A l}}{\lambda_{C u}} \cong 0.593
$$

where the thermal conductivities are $387.7 \mathrm{Wm}^{-1} \mathrm{~K}^{-1}, 230 \mathrm{Wm}^{-}$ ${ }^{1} \mathrm{~K}^{-1}$ and $0.024 \mathrm{Wm}^{-1} \mathrm{~K}^{-1}$ for copper, aluminum and air respectively $\left(20^{\circ} \mathrm{C}\right)$.

However despite this ratio, if (6) is calculated for the same winding fill factor for both materials, the cross slot thermal conductivity is only fractionally lower in the aluminum winding (a difference of just $50 \mu \mathrm{Wm}^{-1} \mathrm{~K}^{-1}$ ). Predicted cross slot thermal conductivities for both aluminum and copper coils are therefore $0.168 \mathrm{Wm}^{-1} \mathrm{~K}^{-1}$ with a $75 \%$ fill factor. This is due to the dominant factor being the very low thermal conductivity of the air between the winding strands.

Measurement of cross coil thermal conductivities has shown that actual thermal conductivity is $2.03 \mathrm{Wm}^{-1} \mathrm{~K}^{-1}$, for a $77 \%$ fill factor. This shows that the assumption that the coil insulation can be disregarded is false. If the air is replaced by the enamel material, polyamide, which has a reported thermal conductivity of $0.27 \mathrm{Wm}^{-1} \mathrm{~K}^{-1}$ at $23^{\circ} \mathrm{C}$, in (6), the revised prediction of $2.14 \mathrm{Wm}^{-1} \mathrm{~K}^{-1}$, is much closer to the test results. It should be noted that this is much higher than in a coil with lower fill factor, even if an encapsulation material with similar properties to the winding enamel is considered, with a $50 \%$ fill factor having a cross slot conductivity of $0.84 \mathrm{Wm}^{-1} \mathrm{~K}^{-1}$. This will be reported in more detail in a future paper.

\section{Minimised Mass}

An advantage of aluminum is its low mass density when compared to copper. The mass density of copper $\left(\rho_{C u}\right)$ is 8940 $\mathrm{kg} / \mathrm{m}^{3}$ and aluminum $\left(\rho_{A l}\right)$ is $2700 \mathrm{~kg} / \mathrm{m}^{3}$. The mass ratio of the two windings is given by:

$$
\partial_{\text {mass }}=\frac{m_{A l}}{m_{C u}}=\frac{\rho_{A l} S_{F F}^{A l}}{\rho_{C u} S_{F F}^{C u}} \cong 0.302 \frac{S_{F F}^{A l}}{S_{F F}^{C u}}
$$

Therefore even factoring in the extra volume of aluminum required for a fixed DC loss (from Eqn. 1), the mass is still $50 \%$ that of the copper winding.

\section{E. Minimised Cost}

At 2014 prices [15], aluminum is $\$ 1.95 / \mathrm{kg}$ and copper $\$ 6.50 / \mathrm{kg}$. Therefore aluminum windings will be $10 \%$ of the price of copper windings for a given fill factor, or $15 \%$ of the price of copper windings for a fixed DC loss. 


\section{F. Summary}

The use of Aluminum conductors appears to offer advantages in terms of cost and mass whilst having minimal impact on thermal conductivity.

Overcoming the limitation of the low electrical conductivity of the material is therefore important, with the use of precompression of the coils being a proven way of addressing this [7]. Owing to the high electrical frequency in this application, stranded conductors are required in mitigation of AC loss and this poses particular challenges in the manufacture of precompressed coils.

\section{Challenges FOR PRE-COMPRESSED COILS WITH Multi STRAND WINDINGS}

In [7] single-strand aluminum coils were developed, which embedded the coil termination in the coil during compression. The process used high pressures (up to $250 \mathrm{MPa}$ ) in order to compress the windings to close to their theoretical maximum fill factor; when both conductor and winding insulation is taken into account, less than $0.5 \%$ air would remain in the coil. This allows gross conductor to slot fill factors of more than $75 \%$ to be achieved. Testing showed these coils to be robust, with no winding shorts being identified during motor testing.

In [16] the process was improved for a single strand coil, in order to allow coil terminations to remain outside of the compression zone during the compression process. However in the latter case great care needed to be taken in order to avoid damaging the part of the conductor in the transition between compressed coil and uncompressed termination. This problem would be even more acute for a set of small diameter, stranded conductors, with there being a high risk of shearing of conductors and damage to conductor insulation during compression.

\section{PRE-COMPRESSED COIL DESIGN}

The coil is manufactured in stages, using tooling comprising a die, bobbin and punch (Fig. 3). Firstly the stranded conductors are wound onto a bobbin. The wound coil is then compressed in the void left by the assembled bobbin, punch and die. This is physically a much larger set of tooling than that manufactured previously $[7,16]$ with the coils having dimensions of $223 \mathrm{~mm}$ long, $90 \mathrm{~mm}$ width and $30 \mathrm{~mm}$ height.

The bobbin, punch and die assembly is designed such that the coil is over-compressed by circa $2 \%$, allowing the coil to spring back, following compression, by the circa $1 \%$, plus margin, as observed previously [7].

Calculations were undertaken in order to decide the layup of the coils on the bobbin, Fig. 4. To achieve the target torque speed curve with the available DC link voltage and current capability (from Table 1), the machine would be wound with 30 turns per coil. An analysis of AC winding losses at both base speed, peak power and also at maximum speed, peak power were undertaken. These suggested that the use of transposed aluminum conductors with a diameter of $1.4 \mathrm{~mm}$ would result in acceptable AC losses; stated as a percentage of DC winding loss, AC losses would be only $5 \%$ at base speed and $50 \%$ at maximum speed. Transposition of conductors was considered essential to minimize circulating currents, avoiding any imbalance in flux between winding strands; a high risk as precise strand location could not be guaranteed. A single transposition per turn was specified so as to limit the detrimental effect of stand transposition on coil fill factor, with heavily transposed conductors having significantly increased effective cross section compared to those with parallel conductors [17].

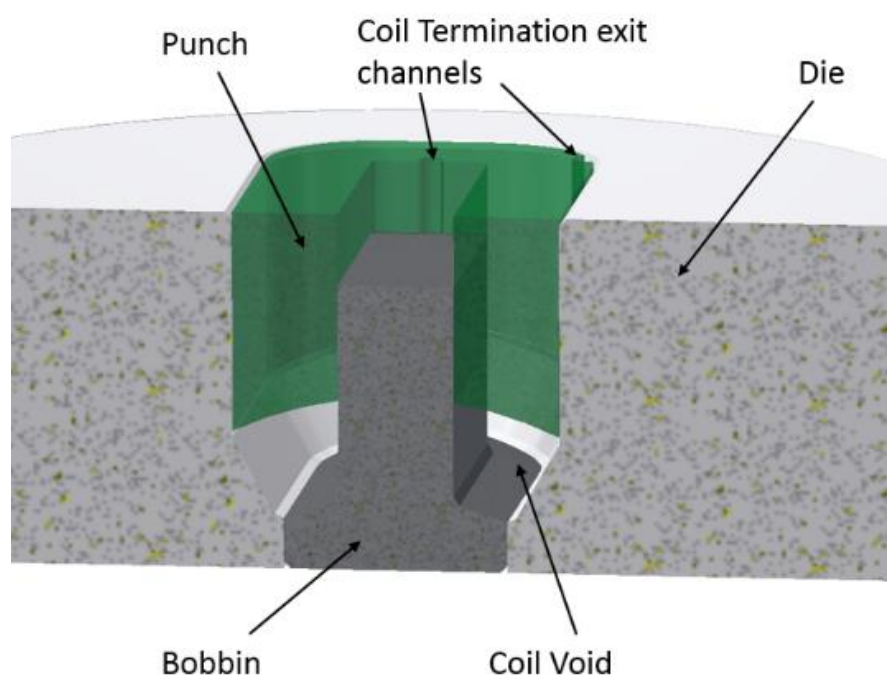

Fig. 3: Coil Compression bobbin, die and punch 3D CAD model, shown in section.

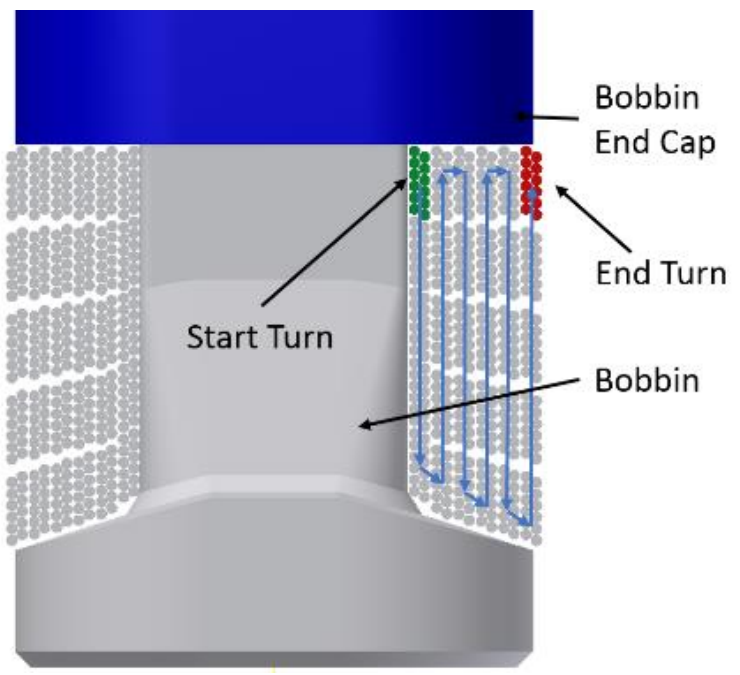

Fig. 4: Winding layup onto bobbin, prior to coil compression.

It would therefore be necessary to use a 12 strand coil to maximise the fill factor, with the aim of achieving $77.9 \%$ (coil to slot). The limiting influence on compressed coil fill factor is insulation thickness, [8]. Whilst the fill factor in the slot would be $77.9 \%$, when slot liners $(0.3 \mathrm{~mm}$ Nomex assumed $)$ and the 
maintenance of a reasonable clearance between coil and airgap are taken into account the fill factor of the coil itself would be $88.4 \%$. This fill is predicted to provide a phase resistance of $46 \mathrm{~m} \Omega$ (two series coils).

The IEC60317 standard defines the maximum thickness for the enamel used in different grades and classes of winding wire. For the Grade 2, Class H conductor to be used with this machine, average wire diameter including the enamel coating will be $1.486 \mathrm{~mm}$, an increase of $6 \%$ in diameter compared to the bare conductor alone; therefore a $12 \%$ increase in cross sectional area. Taking this into consideration, overall coil fill (including insulation) can be shown to be $99.5 \%$, extremely close to the absolute limit. In fact, if the maximum diameter strands (including enamel coating) specified in IEC60317 were used $(1.502 \mathrm{~mm})$ this would result in a coil packing factor of $101.7 \%$ (conductor plus enamel to available coil cross sectional area). Although it was proven to possible to compress coils for the prototype, a more realistic limit of $87 \%$ (conductors to coil cross sectional area) is preferable, allowing also for the use of conductors with enamel thickness at the maximum limit allowed in the standard. This would reduce slot fill factor to around the original objective of $75 \%$.

The use of 30 turns per coil facilitates the formation of a winding from six layers of five turns (Fig. 4), such that both start and finish conductors may be positioned at the top of the coil. Here the stranded coils are shown flattened; experimentation has showed that stranded wire tends to flatten in this way when bobbin wound. The coil compression tooling was designed with particular features to allow the start and finish conductors to exit the tooling without being compressed, as shown in Fig. 3.

When compared to the coils manufactured previously, these much larger coils require a larger force to compress them. For the earlier coils [7] a force of $150 \mathrm{kN}$ (15 tonnes, equating to a pressure of $250 \mathrm{MPa}$ ) was sufficient to compress the coils. For this new coil, with a surface area 26.5 times greater, a force of $4000 \mathrm{kN}$ (or 400 tonnes) was required to achieve the same pressure.

The coils are mounted to a segmented stator arrangement. As this machine has a single layer winding, alternate teeth are wound. The stator is therefore designed with two different tooth designs: one to accommodate the windings and the other between coils (Fig. 5). The stator segments are designed such that when assembled they would lock together, with the objective of minimizing residual gaps and any stator eccentricity.

\section{COIL MANUFACTURE}

Coil compression tooling was manufactured from high strength tool steel (Fig. 6).

The coil was wound onto the bobbin, following the pattern illustrated in Fig. 4. A two stage compression process was then followed. The first stage of the process involved fitting the bobbin into the die and then covering the coil with the punch.
Coil terminations were laid in specially prepared slots in the punch and die in order to prevent them being sheared during pressing. The punch, die and bobbin assembly was then initially compressed to approximately 30 tonnes and the 'blank' coil extracted.

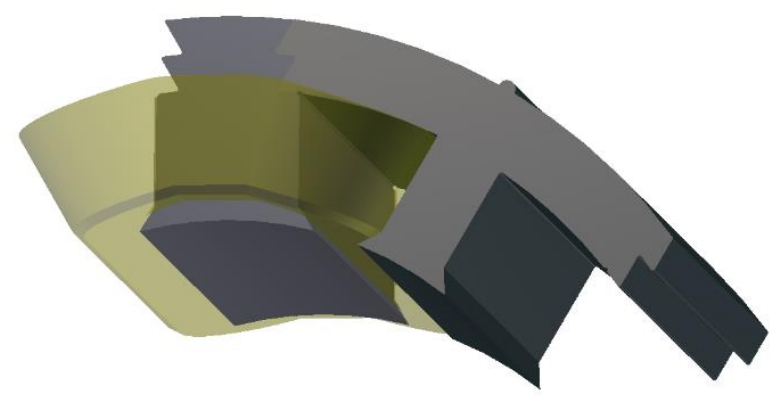

Fig. 5: Segmented stator design used with pre-compressed aluminum coils.

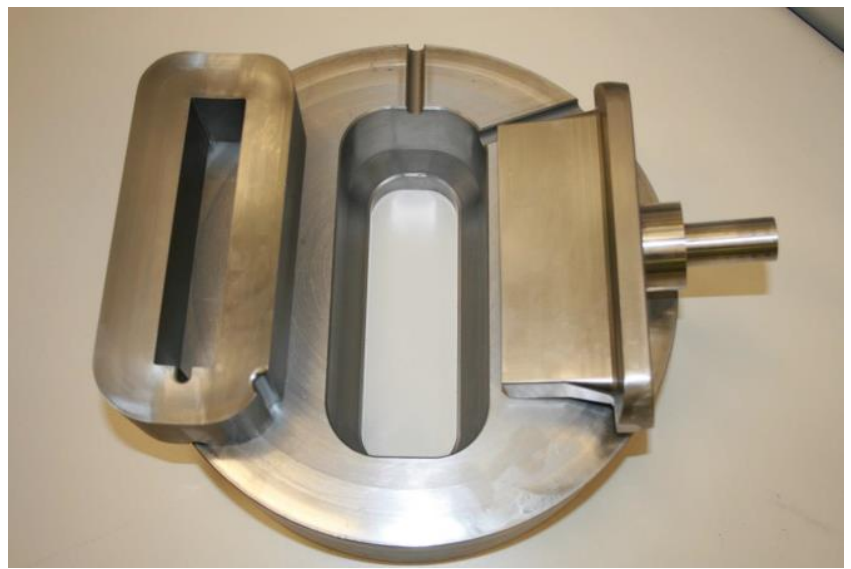

Fig. 6: Showing punch (left), die (bottom) and bobbin (right) set.

The bobbin was reassembled with the die, with the addition of two plastic inserts: one to the base of the coil and one at the top. These inserts were found to be required, as under full compressive pressure the compression tooling was plastically deforming and some of the conductor aluminum was extruding between the different parts of the tooling, as shown in Fig. 7.

These inserts were 3D printed for prototype manufacture; the lower insert is shown fitted in the die in Fig. 7, where it occludes the gap between die and bobbin. A top insert was also used which took the form of a $2 \mathrm{~mm}$ thick conformal sheet, placed over the top of the coil. These inserts proved successful and prevented the extrusion of the aluminum during prototyping, with the plastic instead being sacrificially extruded. However further analysis predicts that hardening of the tooling would prevent it from deforming, avoiding damage to the conductors without the need for additional components.

During the second compression cycle, acrylic, heat resistant braid was used to cover the winding terminations where they transition from inside to outside of the compressed volume of the coil. This provided a level of abrasion protection to these vulnerable parts during coil compression. 
With both inserts fitted, the coil was compressed under full pressure (250MPa, equating to 400 tonnes); Fig. 8 shows the coil in position on the press. Force was steadily increased until the required pressure was applied and then held for 1 minute; the pressure was then released and reapplied again for a further minute; this method was used as a method of work hardening the coil and therefore decreasing spring-back after pressing. Spring-back was measured to be $1.2 \mathrm{~mm}$, equating to $4.5 \%$. This is higher than seen previously [7] and is thought to be due to the elastic behaviour of the plastic inserts; however, the movement is within the allowable tolerance.

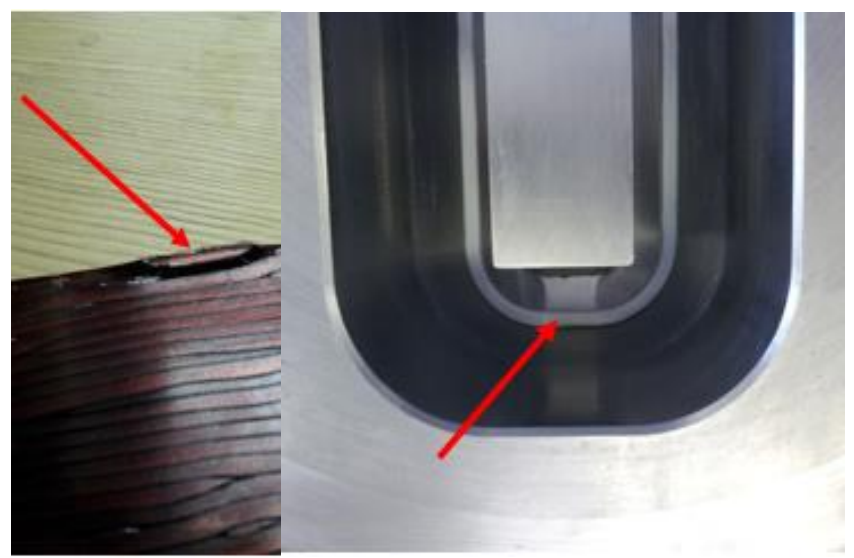

Fig. 7: Showing (left) how aluminum wire extruded between die tooling under compression and (right) insert used to address this issue.

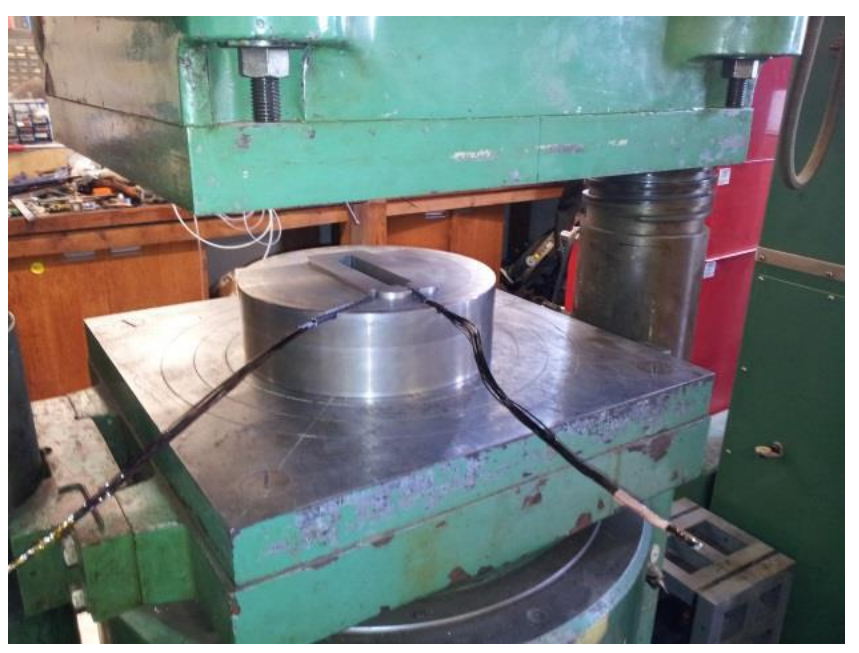

Fig. 8: Die tooling positioned in 500 tonne press ready for compression. Wire terminations are shown laid flat in specially prepared channels.

Finally the bobbin and punch were pressed out from the die and the coil manually removed from the bobbin, with the inserts and braided sleeves removed. Close up detail of a finished coil is shown in Fig. 9.

\section{PRE-COMPRESSED COIL TEST}

\section{A. Coil static testing}

Finished coils were visually inspected for damage and either repairs made to correct minor flaws (slight abrasions) or the coils rejected if more significant problems were identified. Undamaged coils were tested to $1 \mathrm{kV}$ using a commercially available surge tester, designed to detect turn to turn faults. All coils were found to successfully pass these tests.

The coils where then fitted to the stator and further electrically tested. Testing included 'Mega' and 'HiPot' tests at $1.5 \mathrm{kV}$ for the detection of shorts to earth, as well as a further surge test for turn to turn shorts at up to $1 \mathrm{kV}$. Again all tests were passed.

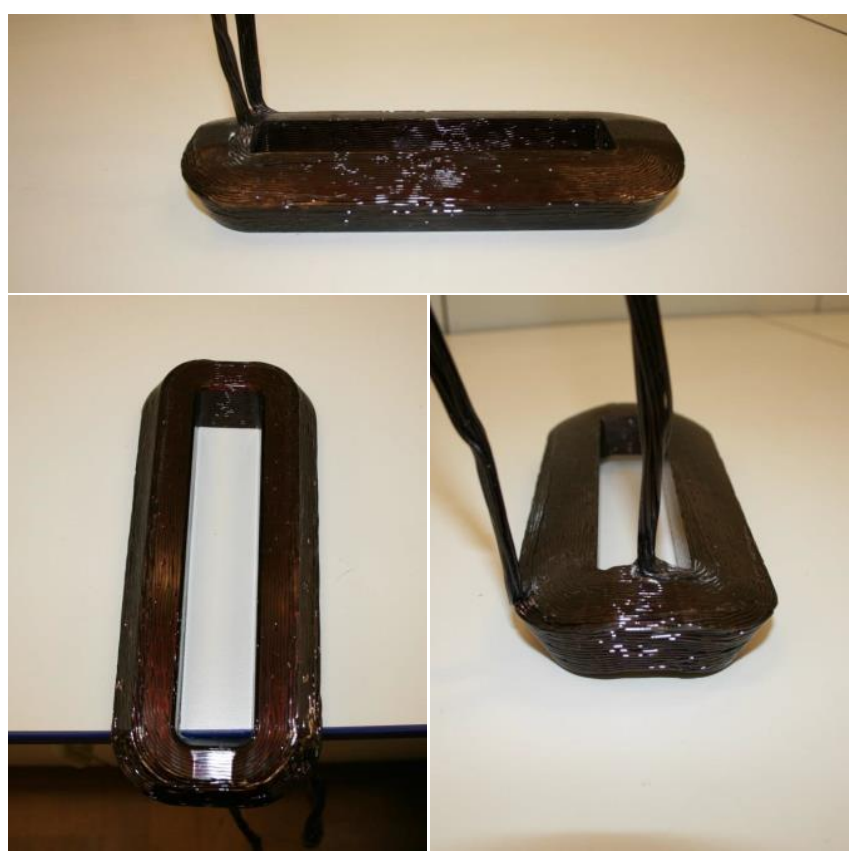

Fig. 9: Pre-Compressed Aluminum Motor coil with $77.9 \%$ gross fill factor following compression.

Coil resistance was measured and found to be $0.023 \Omega$ as predicted, confirming the $77.9 \%$ fill factor (coil to slot). For the purposes of comparison, a conventional bobbin wound coil, using uncompressed stranded and transposed copper wire, was made and found to have a fill factor of $39 \%$. This equated to a winding resistance of $0.028 \mathrm{ohms}$; this fill factor was comparable to that observed in the stranded and transposed aluminum wires prior to compression, suggesting that the compression process reduced coil volume by approximately $50 \%$.

The aluminum coil was found to have a mass of $0.78 \mathrm{~kg}$, whilst the higher resistance copper coil is estimated to weigh $1.38 \mathrm{~kg}$. This equates to an overall active mass saving of $3.4 \mathrm{~kg}$ for the full motor (10.4\% of motor active mass).

\section{B. Motor Thermal Testing}

One of the limitations of pre-compressed coils is that they are difficult to instrument for temperature measurement; the compression process means that an inserted thermocouple will either be destroyed or lead to turn-to-turn shorts inside the compressed coil. As a result it is difficult to experimentally 
verify peak coil temperatures.

Thermal modelling of the motor was undertaken using the JMAG Finite Element toolset. This modelling was formed of two elements. Firstly a thermal finite element model (Fig. 10), containing motor active components and slot insulation, and secondly a thermal network (Fig. 11) defining heat transfer between stator and rotor [18] and to the water jacket. The material properties assumed are shown in Table 2.

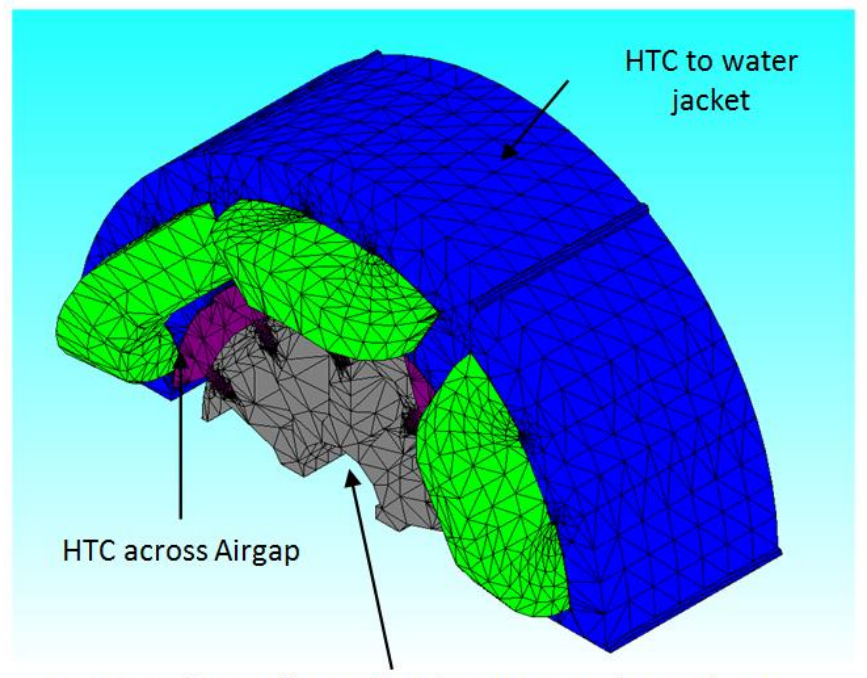

Heat transfer coefficient (HTC) to water jacket via bearings (thermal resistance)

Fig. 10. Finite element model used for motor thermal analysis.

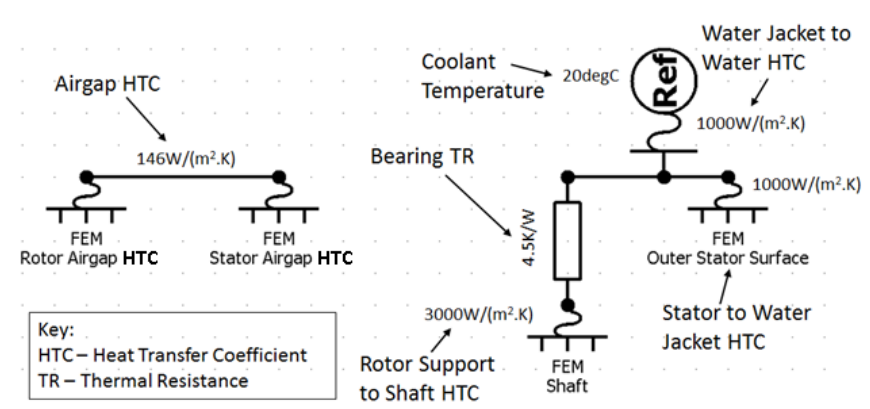

Fig. 11. Thermal network used in thermal analysis.

TABLE 2. MATERIAL PROPERTIES ASSUMED IN THERMAL ANALYSIS

\begin{tabular}{|l|l|l|l|l|}
\hline & Laminations & Coils & $\begin{array}{l}\text { Slot } \\
\text { Liner }\end{array}$ & $\begin{array}{l}\text { Rotor } \\
\text { Support }\end{array}$ \\
\hline Material & $\mathrm{M} 270-35$ & Aluminum & Nomex & Aluminum \\
\hline Density & 7650 & 2699 & 1000 & 2699 \\
& $\mathrm{~kg} / \mathrm{m}^{3}$ & $\mathrm{~kg} / \mathrm{m}^{3}$ & $\mathrm{~kg} / \mathrm{m}^{3}$ & $\mathrm{~kg} / \mathrm{m}^{3}$ \\
\hline Specific Heat & 460 & 900 & 260 & 900 \\
Capacity & $\mathrm{J} /(\mathrm{kg} . \mathrm{K})$ & $\mathrm{J} /(\mathrm{kg} \cdot \mathrm{K})$ & $\mathrm{J} /(\mathrm{kg} . \mathrm{K})$ & $\mathrm{J} /(\mathrm{kg} . \mathrm{K})$ \\
\hline Thermal & 23 & 230 & 0.2 & 230 \\
Conductivity & $\mathrm{W} /(\mathrm{m} . \mathrm{K})$ & $\mathrm{W} /(\mathrm{m} . \mathrm{K})$ & $\mathrm{W} /(\mathrm{m} . \mathrm{K})$ & $\mathrm{W} /(\mathrm{m} . \mathrm{K})$ \\
\hline
\end{tabular}

This modelling was validated through static thermal testing of the prototype motor, with adjustments made to the thermal model in order to achieve consistency. Validation was undertaken at several different levels of winding loss, with DC current injected in order to achieve winding losses in $1 \mathrm{~kW}$ steps to $5 \mathrm{~kW}$, representing the range of copper losses expected.
Fig. 12 shows the results of one test, undertaken for $2 \mathrm{~kW}$ of copper loss, demonstrating the good correlation between the model and test motor; this is also representative of the other tests undertaken. Coils were then modelled with anisotropic thermal conductivities in the wound and cross slot directions. From the discussion earlier in Section III.C, a thermal conductivity of $230 \mathrm{Wm}^{-1} \mathrm{~K}^{-1}$ was assumed in the axial direction with $2.03 \mathrm{Wm}^{-1} \mathrm{~K}^{-1}$ being assumed across the slot (see Section III.C.). This was implemented in the model for different levels of winding loss and this predicted that peak winding temperatures would be within $5 \%$ of the measured end-winding temperature in coils with this high fill factor.

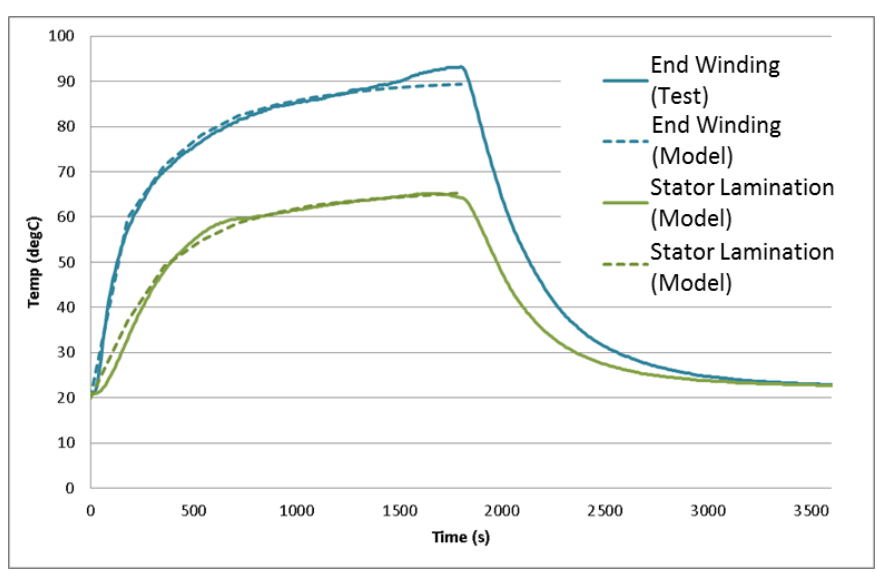

Fig. 12. Motor thermal performance; comparison between test data and thermal model for $2 \mathrm{~kW}$ of copper loss.

Thermal testing highlighted the importance of correctly terminating aluminum motor windings. With a first prototype machine, thermal runaway was observed in the motor windings following repeated thermal tests. Analysis showed that this was due to the use of the incorrect termination crimps.

During repeated heating the crimped aluminum tails had suffered oxidation, leading to an increase in crimp joint resistance. This problem was avoided in later prototypes by the use of specialist crimps containing an antioxidant compound which prevents oxidation, meaning that crimp resistance remained constant during thermal cycling.

\section{COMPARISON WITH COPPER WOUND MACHINES}

Whilst comparable copper wound machines have not been built and tested, designs have been generated for machines with both pre-compressed copper windings and also with more conventional bobbin wound coils (Table 3). Comparative predictions can therefore be made based on the earlier findings of this paper. All machines feature transposed conductors and therefore AC losses, due to parallel path effects, are assumed to be minimized. A loss comparison is made at maximum speed / power, where AC losses are highest, in order to illustrate the scale of these losses in such high frequency electrical machines; AC winding losses will be less significant in other parts of the operating envelop. 
TABLE 3. COMPARISON BETWEEN ALUMINUM PRE-COMPRESSED WINDINGS AND TWO TYPES OF COPPER WINDING.

\begin{tabular}{|l|l|l|l|}
\hline & $\begin{array}{l}\text { Pre- } \\
\text { Compressed } \\
\text { Aluminum }\end{array}$ & $\begin{array}{l}\text { Pre- } \\
\text { Compressed } \\
\text { Copper }\end{array}$ & $\begin{array}{l}\text { Bobbin } \\
\text { Wound } \\
\text { Copper }\end{array}$ \\
\hline Turns & 30 & 30 & 30 \\
\hline Strands & $12(1.4 \mathrm{~mm})$ & $12(1.4 \mathrm{~mm})$ & $12(1.0 \mathrm{~mm})$ \\
\hline Fill Factor & $77 \%$ & $77 \%$ & $39 \%(2)$ \\
\hline Coil Mass & $0.78 \mathrm{~kg}$ & $2.48 \mathrm{~kg}$ & $1.38 \mathrm{~kg}$ \\
\hline Coil Cost (1) & $\$ 1.46$ & $\$ 16.12$ & $\$ 8.97$ \\
\hline Coil DC Resistance & $46 \mathrm{~m} \Omega$ & $28 \mathrm{~m} \Omega$ & $56 \mathrm{~m} \Omega$ \\
\hline $\begin{array}{l}\text { DC Winding Loss } \\
(\mathbf{1 0 , 5 0 0 r p m , ~ 8 0 k W )}\end{array}$ & $3.19 \mathrm{~kW}$ & $1.94 \mathrm{~kW}$ & $3.64 \mathrm{~kW}$ \\
\hline $\begin{array}{l}\text { AC Winding Loss } \\
(\mathbf{1 0 , 5 0 0 r p m , ~ 8 0 k W )}\end{array}$ & $1.33 \mathrm{~kW}$ & $2.17 \mathrm{~kW}$ & $0.57 \mathrm{~kW}$ \\
\hline $\begin{array}{l}\text { Total Winding } \\
\text { Loss (10,500rpm, } \\
\text { 80kW) }\end{array}$ & $4.52 \mathrm{~kW}$ & $4.11 \mathrm{~kW}$ & $4.21 \mathrm{~kW}$ \\
\hline
\end{tabular}

(1) Material costs from [15] (US Dollars).

(2) Experimentally validated, see Section VII.A.

The pre-compressed copper coil has a $\sim 40 \%$ lower DC resistance than the aluminum coil, due to differences in material electrical conductivity. However this is offset by higher $\mathrm{AC}$ losses meaning that, at this operating point, total winding loss is only $10 \%$ higher in the aluminum coil. Equally the pre-compressed copper windings have mass 3.3 times higher and cost 11 times more than for the pre-compressed aluminum coil.

When compared to a more conventional bobbin wound copper winding, as reported in Section VII.A, the aluminum coil has a $18 \%$ lower DC resistance, whilst once again having much lower mass (factor of 1.8) and cost (factor of 6). However in this case the AC losses in the aluminum coil are much higher than for the copper winding; in this case the lower conductivity of the aluminum conductors is offset by the use of much smaller conductor strands in the lower fill factor copper coil (as predicted in Section III.B).

This means that, at this operating point, total winding losses would be $7 \%$ higher in the aluminum wound machine. Even this delta could be overcome by the use of a larger number of winding strands in the coils, however this could be expected to also lead to some reduction in fill factor (with smaller conductors there would be a larger ratio of winding insulation to conductor material).

\section{CONCLUSIONS}

The paper has shown how pre-compressed motor winding coils can be constructed from stranded and transposed aluminum winding wire. The use of these coils allows the lower conductivity of aluminum to be overcome by enabling higher fill factors, with $77.9 \%$ being achieved in this case; reducing uncompressed coil volume by around 50\%. The process allows AC winding losses to be reduced to acceptable levels through facilitation of the use of stranded and transposed wire, and this created challenges in protecting coil terminations during the pressing process. These challenges were overcome through a combination of careful design and protective measures during manufacture.

The use of pre-compressed aluminum coils, by comparison with the same machine having conventional bobbin wound copper coils with similar stranding, resulted in an $18 \%$ lower DC winding resistance, reduced overall motor mass by $10 \%$ and the winding raw material cost by $84 \%$. AC winding losses are however higher, though this could be overcome by increasing the number of winding strands in the precompressed winding, with some detriment to fill factor.

This pre-compression process can also be applied to machines featuring copper windings, offering improvements in fill factor, again in particular where stranded coils are necessary. However in this case the much higher AC losses expected must be carefully managed, again potentially through the uses increased stranding.

This technology has allowed for the construction of a rareearth magnet free Segmental Rotor SRM offering similar performance to the IPM motor used in the Nissan Leaf, whilst having a similar mass. Whilst the motor is larger than that in the Nissan Leaf, it would also be significantly cheaper in terms of material content. Questions remain as to the long term reliability of these coils as well as scalability of the current manufacturing process to a series production environment; further work is therefore now concentrated on addressing these concerns.

\section{REFERENCES}

[1] Yanniello, B., "Aluminum - The Other Conductor," Eaton Electrical Inc., 2006.

[2] Larry Pryor, R.S., Bill Brownell, "A Comparison of Aluminum vs. Copper as Used in Electrical Equipment," GE Consumer \& Industrial, 2008.

[3] Exchange, L.M. (2013, 15th February). Settlement prices. Available: http://www.lme.com/home.asp

[4] Björn, K. and Jan-Ove, J., "Recycling of electrical motors by automatic disassembly," Measurement Science and Technology, vol. 11, p. 350, 2000.

[5] Dymond, J.H. and Findlay, R.D., "Some commentary on the choice of rotor bar material for induction motors," Energy Conversion, IEEE Transactions on, vol. 10, pp. 425-430, 1995.

[6] Poloujadoff, M., Mipo, J.C., et al., "Some economical comparisons between aluminium and copper squirrel cages," Energy Conversion, IEEE Transactions on, vol. 10, pp. 415-418, 1995.

[7] Widmer, J.D., Spargo, C.M., et al., "Solar Plane Propulsion Motors With Precompressed Aluminum Stator Windings," Energy Conversion, IEEE Transactions on, vol. 29, pp. 681-688, 2014.

[8] Jack, A.G., Mecrow, B.C., et al., "Permanent magnet machines with powdered iron cores and pre-pressed windings," in Industry Applications Conference, 1999. Thirty-Fourth IAS Annual Meeting. Conference Record of the 1999 IEEE, 1999, pp. 97-103 vol.1. 
[9] Widmer, J.D., Martin, R., et al., "Electric vehicle traction motors without rare earth magnets," Sustainable Materials and Technologies, 2015.

[10] Mecrow, B.C., El-Kharashi, E.A., et al., "Preliminary performance evaluation of switched reluctance motors with segmental rotors," Energy Conversion, IEEE Transactions on, vol. 19, pp. 679-686, 2004.

[11] Widmer, J.D. and Mecrow, B.C., "Optimised Segmental Rotor Switched Reluctance Machines with a Greater Number of Rotor Segments than Stator Slots," IEEE Transactions on Industry Applications, 2013.

[12] Widmer, J.D., Martin, R., et al., "Optimization of an 80-kW Segmental Rotor Switched Reluctance Machine for Automotive Traction," IEEE Transactions on Industry Applications, 2015 (In Press).

[13] Sato Y., I.S., Okubo T., Abe M. and Tamai K., "Development of High Response Motor and Inverter System for the Nissan LEAF Electric Vehicle," presented at the SAE 2011 World Congress \& Exhibition, Detroit, Michigan, United States, 2011.

[14] Sullivan, C.R., "Computationally efficient winding loss calculation with multiple windings, arbitrary waveforms, and two-dimensional or threedimensional field geometry," Power Electronics, IEEE Transactions on, vol. 16, pp. 142-150, 2001.

[15] (2014, 9th December). London Metal Exchange. Available: https://www.lme.com/

[16] Ifedi, C., "A High Torque Density, Direct Drive InWheel Motor for Electric Vehicles," PhD, School of Electrical and Electronic Engineering, Newcastle University, Newecastle-upon-Tyne, 2013.

[17] Sullivan, C.R., "Optimal choice for number of strands in a litz-wire transformer winding," Power Electronics, IEEE Transactions on, vol. 14, pp. 283291, 1999.

[18] Staton, D., Boglietti, A., et al., "Solving the More Difficult Aspects of Electric Motor Thermal Analysis in Small and Medium Size Industrial Induction Motors," Energy Conversion, IEEE Transactions on, vol. 20, pp. 620-628, 2005. 